04

\title{
Изменение текстуры поверхности полимерных материалов в пылевой плазме
}

\author{
( В.Ю. Карасев, ${ }^{1}$ Е.С. Дзлиева, ${ }^{1}$ А.П. Горбенко, ${ }^{1}$ И.Ч. Машек, ${ }^{1}$ В.А. Полищук, ${ }^{1,2}$ И.И. Миронова ${ }^{1}$ \\ ${ }^{1}$ Санкт-Петербургский государственный университет, \\ 199034 Санкт-Петербург, Россия \\ ${ }^{2}$ Университет ИТМО, \\ 197101 Санкт-Петербург, Россия \\ e-mail: v.karasev@spbu.ru
}

(Поступило в Редакцию 20 июня 2016 г.)

Исследовано изменение текстуры поверхности полимерных частиц в пылевой плазме. Монодисперсные сферические частицы меламин-формальдегида вбрасывались в плазму тлеющего разряда в неоне. При определенном токе разряда и давлении газа в разрядной трубке частицы зависали в плазменно-пылевых ловушках и находились под воздействием плазмы в течение времени от 5 до $25 \mathrm{~min}$. Далее частицы извлекались, а собранный материал изучался с помощью растрового сканирующего электронного микроскопа. Среди полученных результатов установлено изменение диаметра и шероховатости поверхности от времени пребывания частиц в пылевой плазме. Обнаружено, что усредненные на длине оценки абсолютные отклонения всех точек профиля поверхности находились в наноразмерном диапазоне. Установлено время полной деградации частиц в условиях эксперимента.

DOI: 10.21883/JTF.2017.03.44259.1938

Изучение поверхностных слоев различных материалов и их модификации в связи с развитием нанотехнологий является актуальной темой исследований [1-3]. В [4-6] были опубликованы первые данные о воздействии пылевой плазмы на полимерные частицы. В работах было отмечено, что в условиях эксперимента происходит нагревание микрочастиц до температуры выше температуры плазмы. В настоящей работе мы продолжаем исследование частиц меламин-формальдегида, которые под воздействием плазмы уменьшаются в размерах и подвергаются всесторонней модификации поверхности [5-6]. В отличие от первых работ изменение текстуры поверхности определяется не в относительных, а в абсолютных значениях. Также вводится размерный параметр шероховатости поверхности.

Детали экспериментальной установки, в которой проводились вброс, удержание и последующее извлечение частиц, подробно описаны в [5]. В разрядной трубке зажигался стратифицированный тлеющий разряд при условиях: $\mathrm{Ne}, p=40 \mathrm{~Pa}, i=2.5 \mathrm{~mA}$. Монодисперсные сферические частицы меламин-формальдегида (MF-R), которые вбрасывались в плазму разряда, имели диаметр $7.3 \pm 0.4 \mu \mathrm{m}$, плотность $1.5 \mathrm{~g} / \mathrm{sm}^{3}$. В подобранных условиях частицы зависали в плазменно-пылевых ловушках и находились под воздействием плазмы от 5 до $25 \mathrm{~min}$. С помощью методики сбора и извлечения пылевых частиц [7-9] был подготовлен материал для дальнейшего изучения микросфер, побывавших в разряде.

Анализ изменений микрочастиц проводился с помощью растрового сканирующего электронного микроскопа Merlin Zeiss. При обработке полученных снимков использовалась программа анализа полей высот и изображений Gwyddion. В зависимости от времени пребывания частиц MF-R в плазме изменялся их размер и текстура поверхности, при этом сферическая форма сохранялась. В $[5,6]$ высота неровностей на поверхности частиц была определена в условных единицах (на изображениях это
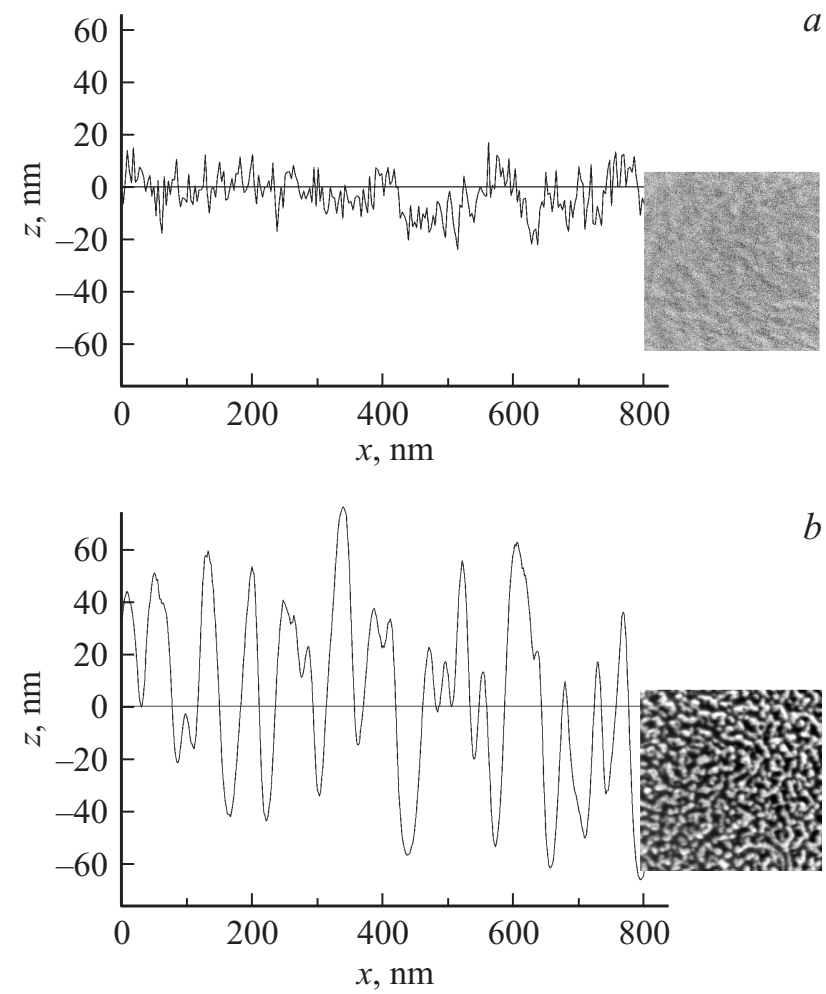

Рис. 1. Текстура поверхности частиц: $a-$ исходные, $b-$ после 20 минут пребывания в плазме в условиях: $\mathrm{Ne}, p=40 \mathrm{~Pa}$, $i=2.5 \mathrm{~mA}$. Справа приведены фрагменты изображений поверхности, полученных на Merlin Zeiss. 


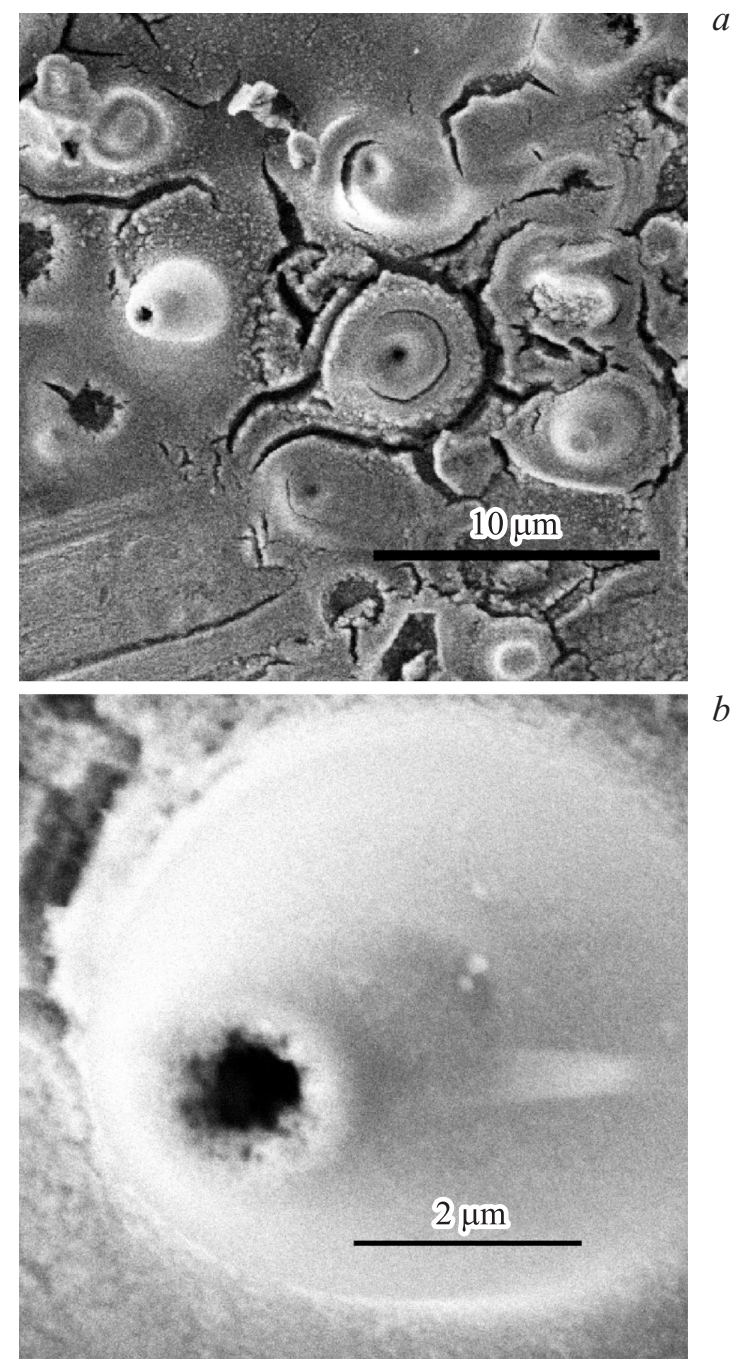

Pис. 2. Деградация частиц MF-R после $30 \mathrm{~min}$ минут пребывания в плазме: $a$ - расплавленные частицы на собирающей платформе, $b-$ изображение одной из частиц в увеличенном масштабе.

соответствовало градациям серого). В настоящей работе были получены размерные данные, характеризующие текстуру поверхности частиц. В частности, как информативный был предложен параметр $R_{a}$, или шероховатость поверхности, которая определяется как усредненное на длине оценки абсолютное отклонение всех точек профиля от средней линии (согласно ГОСТ 25142MF-82):

$$
R_{a}=\frac{1}{N} \sum_{j=1}^{N}\left|r_{j}\right|
$$

Обсудим полученные результаты. На рис. 1 представлены профили поверхности и фрагменты изображений, полученных с помощью электронного микроскопа для исходных частиц и частиц, побывавших в разряде. Средняя линия профиля соответствует нулевому значению высоты $z$, длина оценки - $800 \mathrm{~nm}$. Максимальное отклонение от средней линии оказалось равным: для исходных частиц $23 \pm 5 \mathrm{~nm}(a)$, для модифицированных $65 \pm 7 \mathrm{~nm}(b)$. Усредненное отклонение для исходных частиц $10 \pm 3 \mathrm{~nm}$, для модифицированных $21 \pm 3 \mathrm{~nm}$.

Из рисунка видно, что текстура поверхности частиц под воздействием плазмы изменяется: увеличиваются усредненное и максимальное отклонения от средней линии, также увеличивается расстояние между локальными максимумами. В исходных и в модифицированных частицах абсолютные отклонения от средней линии находятся в наноразмерном диапазоне. Частицы, побывавшие в плазменно-пылевых ловушках $5 \mathrm{~min}$ и более, уменьшаются в диаметре. На временах более $30 \mathrm{~min}$ меламин-формальдегид расплавляется, частицы дергадируют и утрачивают сферическую форму (рис. 2).

До полной деградации частиц в диапазоне от 5 до $25 \mathrm{~min}$ существует зависимость диаметра частиц MF-R и параметра $R_{a}$ от времени пребывания в разряде. Как видно из рис. 3 , изменения размера и шероховатости частиц согласованы между собой. Первые 5-10 min изменения диаметра и шероховатости незначительные. Затем частицы начинают резко уменьшаться в размере и приобретают рельефную, „изрытую“ поверхность (20, $25 \mathrm{~min})$. Характерный изгиб на графиках $a$ и $b(15 \mathrm{~min})$ указывает на изменение скорости деградации поверхности.
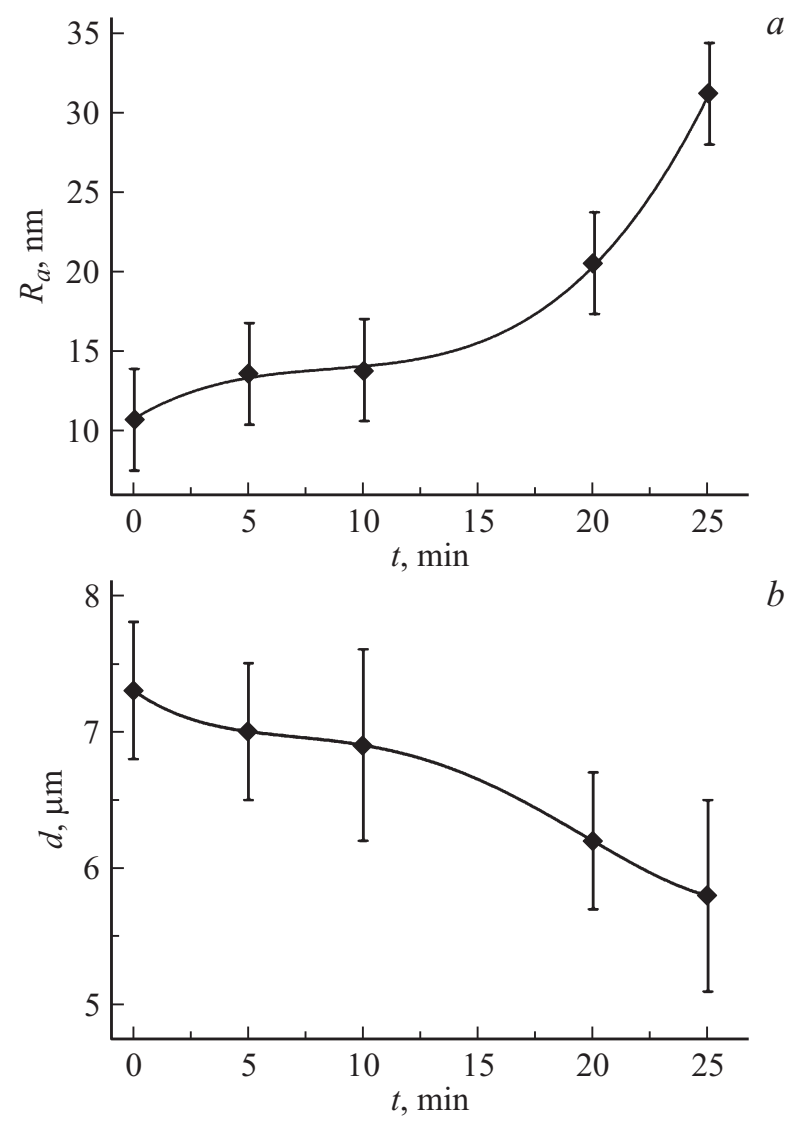

Рис. 3. $a-$ изменение шероховатости поверхности $R_{a}$ в зависимости от времени пребывания в плазме; $b$ - изменение диаметра частиц $d$ в зависимости от времени пребывания в плазме. 
Было сделано предположение [6], что поверхность частиц к этому времени размягчается, а температура приближается к температуре плавления меламинформальдегида $\left(350^{\circ} \mathrm{C}\right)$. В условиях эксперимента определено характерное время для полной деградации частиц диаметром $7.3 \pm 0.4 \mu \mathrm{m}-30 \mathrm{~min}$. В [6] была представлена модель и сделаны численные оценки. Разогрев частиц происходит под воздействием ионного потока, непрерывно идущего на поверхность пылевой частицы в процессе поддержания ее заряда. В условиях эксперимента энергия ионов в низкотемпературной плазме $0.03 \mathrm{eV}$, заряд частиц порядка $1 \cdot 10^{5}$ элементарных, число ионов, попадающих в единицу времени на поверхность частицы, $1 \cdot 10^{9}$. Ионы, ускоренные полем заряженной частицы, достигают энергий порядка $10 \mathrm{eV}$. Такой энергии достаточно, чтобы разогреть частицы MF-R до температуры плавления.

В результате эксперимента и обработки данных было обнаружено следующее:

1) сферические частицы MF-R $7.3 \pm 0.4 \mu \mathrm{m}$ подвергаются всестороннему воздействию плазмы в плазменнопылевых ловушках. В диапазоне от 5 до 25 min сохраняется форма, изменяется диаметр частиц и шероховатость их поверхности;

2) изменение шероховатости согласуется с изменением диаметра частиц на временах от 5 до $25 \mathrm{~min}$, неровности поверхности при этом находятся в наноразмерном диапазоне (до $100 \mathrm{~nm}$ );

3) время полной деградации частиц MF-R $7.3 \pm$ $\pm 0.4 \mu \mathrm{m}$ в неоновой плазме тлеющего разряда при условиях $p=40 \mathrm{~Pa}, i=2.5 \mathrm{~mA}$ составляет $30 \mathrm{~min}$.

Настоящая работа выполнена при поддержке РНФ, грант № 14-12-00094 „Исследование неравновесных самоорганизованных систем в низкотемпературной плазме“. В части электронно-микроскопических исследований - при поддержке гос. задания № 2014/190 Министерства образования и науки РФ.

\section{Список литературы}

[1] Пискарев М.С., Гильман А.Б., Щеголихин А.Н., Шмакова Н.А., Яблоков М.Ю., Кузнецов А.А. // Химия высоких энергий. 2013. Т. 47. № 5. С. 381-388.

[2] Chan C.-M., Ko T.-M., Hiraoka H. // Surf. Sci. Report. 1996. Vol. 24. N 1-2. P. 1-54.

[3] Maurer H.R., Kersten H. // J. Phys. D: Appl. Phys. 2011. Vol. 44. P. 174029.

[4] Карасев В.Ю., Дзлиева Е.С., Ермоленко М.А., Новиков Л.А., Павлов С.И., Эйхвальд А.И., Полишук В.А. // Ученые записки Петрозаводского гос. ун-та. Серия: естественные и технические науки. 2014. Т. 2. № 8 (145). C. 91-96.

[5] Ермоленко М.А., Дзлиева Е.С., Карасев В.Ю., Павлов С.И., Полищук В.А., Горбенко А.П. // Письма в ЖТФ. 2015. Т. 41. Вып. 24. С. 77-82.
[6] Карасев В.Ю., Полишук В.А., Горбенко А.П., Дзлиева Е.С., Ермоленко М.А., Макар М.М. // ФТТ. 2016. Т. 58. Вып. 5. C. $1007-1010$.

[7] Дзлиева Е.С., Ермоленко М.А., Карасев В.Ю. // ЖТФ. 2012. Т. 82. Вып. 7. С. 51-55.

[8] Дзлиева Е.С., Ермоленко М.А., Карасев В.Ю. // Физика плазмы. 2012. Т. 38. № 7. С. 591-596.

[9] Karasev V.Yu., Dzlieva E.S., Ivanov A.Yu., Éikhval'd A.I., Golubev M.S., Ermolenko M.A. // P. Rev. E. Statistical, Nonlinear and Soft Matter Physics. 2009. Vol. 79. N 2. P. 026406_1-6. 